\title{
Agile Augmentation of Clean Air in an Around Fire Cracker Industries Located Villages
}

\author{
Padma .A \\ M. Phil Research Scholar, Gandhigram Rural Institute-Deemed University, Gandhigram, Tamilnadu.-624302
}

\begin{abstract}
Fireworks industries are mostly inevitable to fire, pollution and explosion. The hazardous natures of chemicals are being used during the manufacturing of the crackers. The aim of this study was to study, evaluate and augmentation of clean air in atmosphere from polluted clouds caused by fireworks factories in an around the village. Data on age, sex, education, process, feedback and observations by year on basis collected. The result of the analysis shows that most atmosphere pollution and health illness were caused during manufacturing process like gunpowder application, chemical mixing, chemical handling, testing etc. No infrastructure facility, lack of awareness about characteristics of chemicals and manufacturing process, limited skills is the main reasons for this pollution. In this paper, the causes of pollution and prevention methods are discussed.
\end{abstract}

Key words: Firework industries, crackers, augmentation, gunpowder, characteristics

\section{Introduction}

India is known for leading fire crackers manufacturing industries and plays major role of importance in employment at rural area of our country. About $90 \%$ of India's fireworks industries are located in an around villages of sivakasi taluk at Virudhunagar District of Tamilnadu state .This district is famous for match industries, fireworks and printing industries. The main thriving force of fireworks and match industries in Sivakasi is due to the presence of cheap labor.

During summer, the climate of Virudhunagar District is very hot and dry, which is suitable for manufacture of Crackers and Match industries. There are around 586 fireworks factories in district supporting direct employment to about 72,000 workers and about 1,50,000 numbers of indirect employment in associated works such as paper tube making, wire cutting, box making, tools \&die ,logistics ,printing etc .Crackers are the device that uses explosive, flammable material to create spectacular displays of light, noise and smoke. As its manual unsafe manufacturing process in fireworks industries are inclined to high magnitude of chemical pollution and human health illness.

To reduce the pollution safety norms, awareness and education of process are to be maintained strictly in the manufacturing areas. Fireworks industry is now governing by Inspectorate of Factories and Explosive Act. Since fireworks are situated at village areas, the percentages of educational standards are very less and most of the workers are illiterate, they are not having awareness on handling explosives and flammable chemical materials. All the works are done manually.

Various types and grades of chemicals like Sulfur, Aluminum powder, Barium Nitrate, Potassium Nitrate, Sodium Nitrate, Dextrin, Aluminum chips, PVC powder, Magnesium powder \& Boric acid are handled by unskilled community. All of these chemicals are hazardous in nature because of their flammability and very easy to get mixed with air by unsafe handling. Hence leads to pollution, fire \& explosion.

The various process involved in the fireworks manufacturing are sparkles section, Color pellets, fancy fireworks, filling, fuse cutting, fuse fixing, mixing, packing, sand preparation, sparklers section and weighing of chemicals.

The purpose and focus of this research to indentify the pollution intense manufacturing process, working environment, infrastructure, education \& training, suggestions to minimize the pollution level and other social factors of firework industries.
Objective of Study:
1. To study and examine the manufacturing process which leads pollution.
2. To find out materials and methods were inevitable to Health illness and pollution.
3. To find out new system and procedure to prevent pollution
4. To study the practical applicable methodology to have healthy environment. 


\section{Research Methodology:}

Research was conducted and collected data from high dense populated villages in an around Sivakasi Taluk .Three villages selected namely Salvarpatti, Eravarpatti and vijayaKarisalkulam has total adult population of 9,729 . Strategy plan was administered to collect relevant data. 171 respondents to resulting in responses of required data.

\section{Research Design:}

A well framed local language questionnaire was prepared as a basic tool. The communities, workers and industry management were involved in informal interviews and group discussions to get a clear picture of the real situation in the villages and industries. The questions were designed on the following topics

- Awareness and effect of chemical used in process.

- Detail of safe manufacturing steps and training necessity.

- Examine safe process, required safety measurement and equipments.

- Awareness of health illness due to pollution.

- Identify and implementation of prevention process.

\section{Boundary of the Study:}

1. Study is limited to high dense population whose livelihood dependent on fire work industries.

2. Scope of the research is limited to three villages in an around one taluk of district.

\section{Manufacturing Process:}

In a fireworks industry, different types and grades of chemicals like fuels, oxidizers, igniter, sand and special effect chemicals are mixed thoroughly. Mixing operations are done manually. Homogeneous mixture of chemicals has prepared by manual sieving process by wooden trays with brass mesh at open area. Chemical mixture will filled in compacted paper tubes cracker assembly by manually. The major causes of pollution due to open area activities like Manual mixing, sieving, filling, compacting and loading process.

Charcoal, other chemicals and water are made into paste to overcoat on cotton wicks. After drying, the wicks are cut to required size and fitted suitably on the crackers. The fuses are inserted and allowed to dry. The products are kept at open un even bare surface area of land platforms for drying purpose. The same drying procedures are carried out as more than twice in the production line. Crackers are packed in small boxes manually after satisfactory dryness. Small boxes are bundled together with warning slips on large bundles. The day's production is stored locally and later in the evening, same shifted to the main stores. Push carts and trucks are used to transfer the goods within the factory and to warehouses.

\section{Data analysis:}

Do aware detail steps of manufacturing process and hazardous chemicals nature?

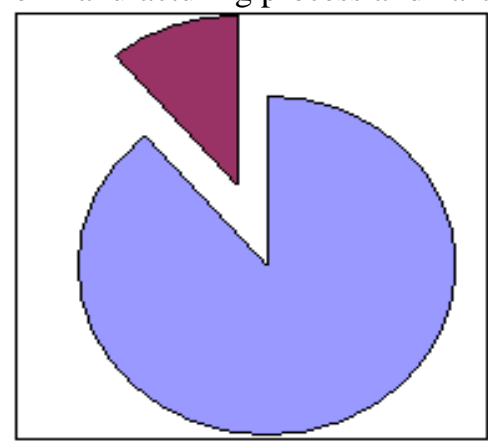

$$
\begin{array}{|l|}
\hline \square \text { NO-89\% } \\
\square \text { YES-11\% }
\end{array}
$$

\section{Interpretation:}

$89 \%$ of workers not aware detail steps of process and the type of chemicals used. Only $11 \%$ respondents had known the process.

\section{Analysis:}

It alarms that the majority of workers have no knowledge about important activity of hazardous process and characteristics of chemicals used. Obviously study emphasizes the importance of awareness among all workers by the management and concern authorities. 
Do training given to respective activity for all workers?
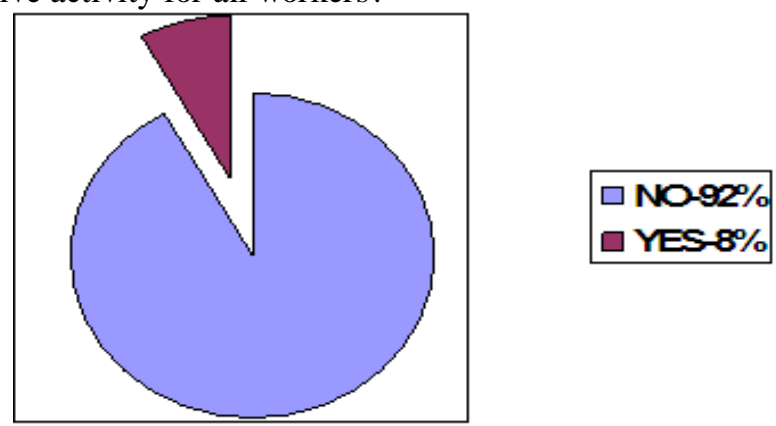

\section{Interpretation:}

$92 \%$ of respondents confirm no training was provided before getting on the job. $8 \%$ of respondents acknowledged the informal training provided while on the job.

\section{Analysis:}

It replicate the majority of workers have no awareness, education \& safety of hazardous process and training before on the job. Researcher emphasizes the importance of training and supervision on regular basis as a mandatory process.

Do aware severity and causes of chemicals in human health due to pollution?

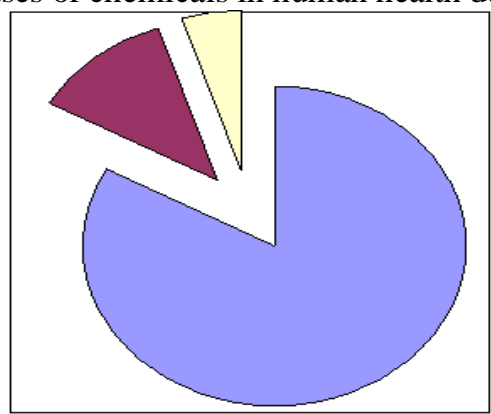

$\square$ YES-83\%

$\square \mathrm{NO}-12 \%$

$\square$ NOIDEA5\%

\section{Interpretation:}

$83 \%$ of respondents indicate awareness of the seriousness of health due to pollution caused by hazardous chemicals $.12 \%$ of respondents particularly from younger age acknowledge the no causes $.5 \%$ of workers confirms their innocence.

\section{Analysis:}

It indicates the majority of workers have awareness about chemical pollution and illness. Researcher strongly advises to take necessary appropriative prevention measures among workers, communities and management.

Is management provides safety tools and attires?
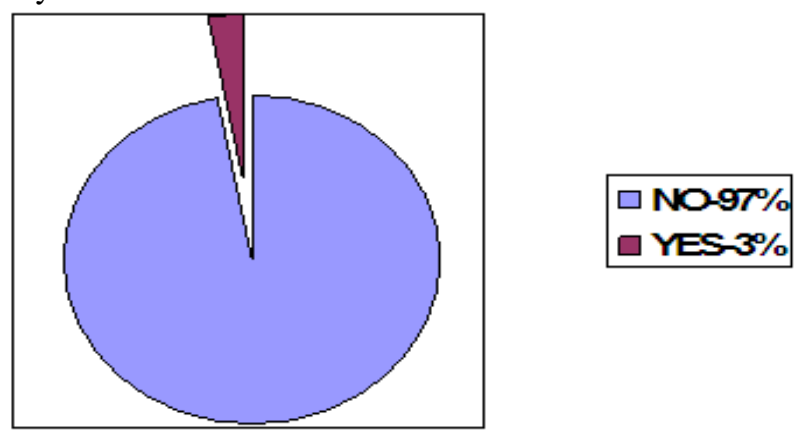

\section{Interpretation:}

$97 \%$ of workers confirm no safety tools and attires provided by management. $.3 \%$ of workers who take care their own precaution by themselves, 


\section{Analysis:}

Study indicates the minimum basic safety attires and tools are not provided by management and respective authorities in hazardous process. Researcher emphasize concern communities to take necessary action with support from Management.

Do need training and awareness program?

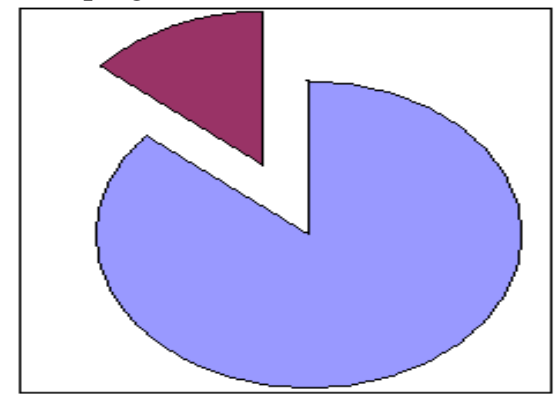

\section{Interpretation:}

$86 \%$ of workers confirm needs of awareness and training program before getting on to the job. $14 \%$ of respondents acknowledged no requirement of training for their particular activity of the job.

\section{Analysis:}

The majority of workers have extended their interest, keenness and importance of training before on the job. Researcher emphasizes the importance of training on regular basis as a mandatory process by the respective management.

Do feel change in your appetite and health illness?

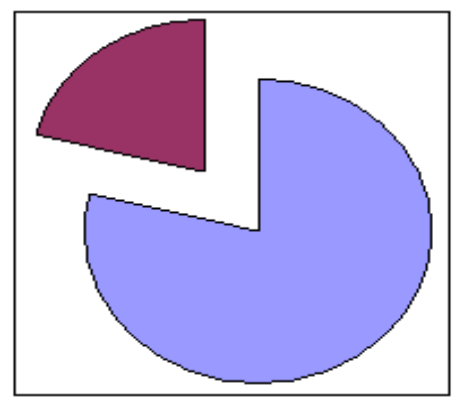

\section{Interpretation:}

$79 \%$ of communities confirms and acknowledged that their appetite drastically changed over the period, which also leads to prolonged health issues. $21 \%$ of respondents unable to correlate with appetite and illness.

\section{Analysis:}

The maximum communities and workers have affected by long health illness and lack of appetite over the decades due to air chemical pollution. Researcher emphasizes the importance of finding ways to control pollution and augmentation of clean air on priority task.

Do agree hazardous chemical plays key role in pollution and health illness?

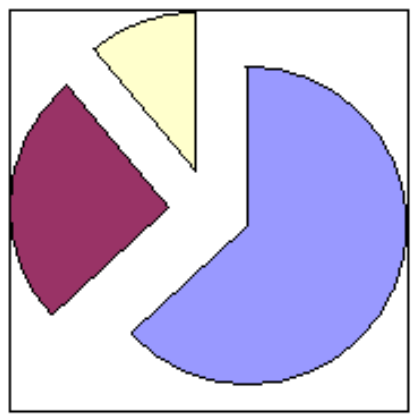

$$
\begin{array}{|l|}
\hline \text { 口 YES-63\% } \\
\text { - NO226\% } \\
\text { 口NOIDEA-11\% }
\end{array}
$$




\section{Interpretation:}

$63 \%$ of respondents agree hazardous chemicals are plays vital aspect for pollution and seriousness of health $.26 \%$ of respondents acknowledged is not a main point for pollution and health illness. $11 \%$ of communities has no awareness about correlated factors.

\section{Analysis:}

Study indicates the majority of communities, workers has agreed and accepted the chemical plays key role for pollution and long health illness .Researcher recommends to take necessary appropriative prevention measures among workers ,communities and management.

\section{Health Record Analysis}

143 male and female workers of a fireworks industry in Sivakasi, Tamil Nadu were subjects of a hair sample study. The samples were analyzed for presence of trace metal elements. It was found that workers had higher levels of Chromium (Cr) and Manganese(Mn) metal traces .Ones having nervous diseases had higher levels of Chromium $(\mathrm{Cr})$, Manganese $(\mathrm{Mn})$ and lead $(\mathrm{Pb})$ presence . A detailed analysis revealed that female workers had higher levels of lead $(\mathrm{Pb})$ and lower levels of $\mathrm{Mn}$ as compared to the male workers. Workers had cases of chronic headaches, dizziness and ulcers due to high level of exposure of Mn during the manufacturing process. Workers didn't wear masks or gloves while working, and hence respiratory tract was deducted as a possible source of entry of the metal into the body.

\section{Findings:} industries.

The key role of the researcher to identify the reason, causes and implication of pollution in fireworks

Reason and causes for pollution:

Dust accumulation during chemical mixing, sieving and filling steps.

Handling of chemicals without protection and safety equipments like protective clothes, gaggles, hand gloves, mask, shoes etc .

Improper stacking / un stacking of chemical filled rings.

Handling of decomposed material.

Leave the unused chemicals without proper disposal .

Unclean the room if spilled chemicals are on the ground.

Weighing of chemicals by iron weigh balance.

Working in open roof.

Improper storage of raw chemicals.

Implication around the village due to pollution:

The researcher identifies the major health illness among the villagers and workers in fireworks industries. Asthma, eye infection. kidney failure and TB are prevalent among 90 per cent of communities/workers due to hazardous chemical pollution in air by fireworks industries in the village.

\section{Potassium Nitrate:}

When inhaled, it causes nose and throat irritation. Higher levels of Potassium Nitrate interfere with the ability of bloody to carry oxygen leading to headaches, methemoglobinemia and kidney problems.

\section{Potassium per Chlorate:}

It causes irritation to skin and eyes. Prolong exposure may affect kidney, white blood cells and thyroid.

\section{Aluminum Compounds:}

It causes irritation to eyes and skin. It also causes metal fume fever which is a flu-like illness with symptoms of metallic taste in the mouth, headache, fever and chills, aches, chest tightness and cough. Exposure to fine dust cause scarring of the lungs with symptoms of cough and shortness of breath.

\section{Barium Nitrate:}

It irritates the nose, throat and lungs. Very high exposure to barium nitrate can cause diarrhea, irregular heartbeat, muscle weakness, tremors, paralysis and even death. It damages the kidney and repeated exposure results in abnormal chest X-ray. 


\section{Copper Chloride:}

It irritates the stomach causing salivation, nausea, vomiting, stomach pain and diarrhea. Repeated exposure can cause shrinking of the inner lining of the nose and may cause ulcers and a hole in the bone dividing the inner nose.

\section{Suggestions:}

Researcher recommends the following adoptable, implementable, mointorable, controllable and upgradable procedure to prevent pollution.

- Thorough education on sensitivity of chemicals and continuous training is strongly recommended on regular intervals.

- The main variable to control pollution and noise level is the particle size of the chemicals. With nano sized aluminum (nAl) particles, the specific surface area increases creating easier ignition and increased burn rates. This will lead to burst the cracker with lesser amount of chemicals with high reactivity. This will also lead to reduce the emission of pollutants during the celebrations.

- The compression of chlorate compositions is in fact hazardous and must be performed in a protected zone.

- Automatic chemical handling and mixing process is strongly recommended.

- Automatic signaling, detectors, smoke sensors, sprinklers and protection system to be implemented.

- Separate places (away from production area) shall help for different types of chemical mixing and handling.

- Entire industry to be covered with lot of dense trees and plantation.

- Trees and plantation should be spray with atomized water particle to absorb chemical dust.

- Manufacturing process posters, warning pictures and chemical name boards should be displayed in detail at every process line.

- Mandatory safety rules to be implemented to wear safety cloth, mask, gloves, rubber shoes while at work

- Workplaces to be monitor /allowed to use with only required quantity of chemical to reduce the probability of dust.

- Testing should be conducted in tight, large enclosures.

\section{Conclusion}

In order to ensure healthy environment by pollution free to have health and safety program, it is essential that there must be strong management commitment, awareness, training, dedicated worker participation, self regulation and discipline to be bought into their regular activities as a part of daily life cycle. An effective management shall address all work-related process, not only those covered by government standards. Safety regulations must be established in all the firework factories. Time to make wakeup call to prevent yet another disaster like Bhopal -Union carbide chemical factory incident.

\section{References}

[1]. http://www.ch.ic.ac.uk/local/projects/gondhia/composition.html.

[2]. Xu-Lin Chen, Yong-Jie Wang, Chang-Rong Wang, Shou-Sheng Li,Gunpowder explosion burns in fireworks factory: causes of death and Management, Burns 28 (2002) 655-658.

[3]. Elham R. Al-Tamimi, MD, A peculiar case of a retained inert piece of Fireworks as an intraocular foreign body in the anterior chamber, Saudi Journal of Ophthalmology (2013).

[4]. Potassium Nitrate, Hazardous Substance Fact sheet, New Jersey Department Of Health and Senior Services.

[5]. Potassium Per chlorate, Hazardous Substance Fact sheet, New Jersey Department of Health and Senior Services.

[6]. Aluminum, Hazardous Substance Fact sheet, New Jersey Department of Health and Senior Services.

[7]. Barium Nitrate, Hazardous Substance Fact sheet, New Jersey Department of Health and Senior Services.

[8]. Copper Chloride, Hazardous Substance Fact sheet, New Jersey Department of Health and Senior Services.

[9]. Sukumar* and R. Subramanian, Trace elements in scalp hair of Manufacturers of fireworks from Sivakasi, Tamil Nadu, The Science of the Total Environment, 114 (1992) 161-168.

[10]. N. Selvakumar, A.Azhagurajan, P. Sheikmohamed, A. Suresh, ballistic Behavior of gunpowder and flash powder for firework chemicals as a function Of particle size. 